Türk. Biyo. Mücadele Derg. 2020, 11 (2): 253-260

DOI:10.31019/tbmd.815552

ISSN 2146-0035-E-ISSN 2548-1002

Orijinal araştırma (Original article)

\title{
Çanakkale ili sebze alanlarında görülen avcı akar türleri
}

\author{
İsmail KASAP ${ }^{1 *}$
}

Predatory mite species in the vegetable growing areas of Çanakkale Province, Turkey

\begin{abstract}
This study was carried out to determine the predatory mite species in vegetable growing areas of Çanakkale Province, Turkey, namely the Ayvacık, Bayramiç, Biga, Çanakkale Central, Eceabat, Ezine, Gelibolu and Lapseki Districts, during the period 2011 to 2015. Five predatory mite species belonging to two families were identified. The family Phytoseiidae, with four genera and four species, was the most important. Typhlodromus athiasae Porath and Swirski and Neoseiulus californicus (McGregor) were the most common species. Another phytoseiid mite species identified during the study was Phytoseiulus persimilis Athias-Henriot.
\end{abstract}

Key words: Çanakkale, Fauna, Predator mite, Phytoseiidae, Vegetable

Öz: Bu çalışma Çanakkale iline bağlı sebze alanlarında bulunan zararlı akarlar üzerinde beslenen önemli avcı türleri saptamak amacı ile 2011-2015 yıllarında, Çanakkale Merkez, Ayvacık, Bayramiç, Biga, Eceabat, Ezine, Gelibolu ve Lapseki ilçelerinde sebze üretim alanlarında yürütülmüsstür. Çalışma sonucunda iki familyaya bağlı beş predatör akar türü tespit edilmiştir. Predatör familyalar arasından Phytoseiidae, dört cinse ait dört tür ile en önemli familya olarak belirlenmiştir. Bu türler içerisinde Typhlodromus athiasae Porath and Swirski ve Neoseiulus californicus (McGregor) en yaygin phytoseiid türleri olarak gözlenmiştir. Çalışmalar süresince saptanan diğer bir phytoseiid ise Phytoseiulus persimilis Athias-Henriot türüdür.

Anahtar sözcükler: Çanakkale, Fauna, Predatör akar, Phytoseiidae, Sebze

\footnotetext{
${ }^{1}$ Çanakkale Onsekiz Mart Üniversitesi, Ziraat Fakültesi, Bitki Koruma Bölümü

* Sorumlu yazar (Corresponding author) e-mail:ikasap@comu.edu.tr ORCID ID:0000-0002-0015-4558

Alınış (Received): 23.10.2020

Kabul ediliş (Accepted): 17.11.2020
} 
Çanakkale ili sebze alanlarındaki avcı akar türleri

\section{Giriş}

Çanakkale ili sebze tarımı açısından oldukça önemli olup, yılda 213.454 hektar alanda sebze tarımı yapılmakta ve yılda toplam 977.602 ton ürün elde edilmektedir (Anonymous, 2019). Bu üretim Marmara Bölgesi üretiminin \%14.28'ini Türkiye sebze üretiminin ise \%3.14'ünü oluşturmaktadır (Anonymous, 2019). Bu kadar geniş bir alanda üretim yapan bölge üreticileri, zararlı akarlara karşı uygulayabilecekleri en kolay yöntem olarak kimyasal mücadeleyi görmekte ve çeşitli avantajlarından dolayı başka bir mücadele yöntemi de düşünmemektedirler. Kimyasal mücadelenin yoğun olarak kullanıldığı alanlarda, çevreye ve insan sağlığına oluşabilecek zararın yanı sıra zararlıların kısa sürede direnç kazanması ve avcı baskısının ortadan kalkması ile popülasyonu Ekonomik Zarar Eşiği (EZE) altında olan mevcut zararlıların, potansiyel zararlı konumuna geçmesi gibi çeşitli sorunlar ortaya çıkabilmektedir. Bu zararlılar içerisinde bitki zararlısı akarlar önemli bir konuma sahiptir ve mücadele yapılmadığı durumlarda önemli ürün kayıplarına neden olabilmektedirler. Doğal dengenin korunduğu ya da geniş etkili tarımsal savaş ilaçlarının kullanılmadığı alanlarda bu akarların önemli bir sorun olmadığı ve populasyon yoğunluğunun düşük seviyelerde olduğu bilinmektedir. Zararlı akarların bu alanlarda kontrol altında tutulmasında en önemli etken ise avcı akar türleridir. (Jeppson et al., 1975; Düzgüneş, 1963, 1977; Göksu, 1968; Yiğit \& Uygun, 1981; Şekeroğlu, 1984; Kasap \& Çobanoğlu, 2007). Bölgede sebze alanlarında yapılan çalışmalarda Tetranychidae (Acari) familyasına bağlı Tetranychus urticae Koch (kırmızı ve yeşil formu) ve Eriophiyidae familyasına bağlı Aculops lycopersici (Masse)'nin en yaygın akar türleri olduğu ve bazı üretim alanlarında önemli zarara neden oldukları, ancak doğal dengenin korunduğu alanlarda ise bu zararlıların popülasyonlarının oldukça düşük seviyelerde olduğu gözlenmiştir (Karagöz \& Kasap, 2011; Uslu, 2012). Ülkemizde Amasya, Ankara, Antalya, Bursa, Tokat ve Yalova gibi illerde sebze alanlarında yapılan çalışmalarda Tetranychidae, Tenuipalpidae ve Eriophyidae familyalarından zararlı akar türleri ve bu akarlar üzerinde beslenen avcı türler saptanarak birbirleri ile ilişkileri belirlenmiştir (Ecevit, 1977; Uysal et al., 2001; İncekulak \& Ecevit, 2002; Kumral \& Çobanoğlu, 2014; 2016). Ayrıca Türkiye'de predatör akarların belirlenmesi ve bazı biyolojik özellikleri ile ilgili pek çok çalışma yayınlanmıştır (Düzgüneş \& Kılıç, 1983; Şekeroğlu, 1984; Çobanoğlu, 1989, 1992, 1997, 2004; Çobanoğlu et al., 2003; Göven et al., 2002; Yanar \& Ecevit, 2005; Faraji et al., 2011; Kumral \& Çobanoğlu, 2014; 2016). Bu çalışmada ise Çanakkale ili sebze alanlarında zararlı akarlar üzerinde beslenen predatör türlerin saptanması amaçlanmıştır.

\section{Materyal ve yöntem}

$\mathrm{Bu}$ çalışmada Çanakkale iline bağlı sebze alanlarında bulunan zararlı akarlar üzerinde beslenen önemli avcı türleri saptamak amacı ile, Çanakkale Merkez, Ayvacık, Bayramiç, Biga, Eceabat, Ezine, Gelibolu ve Lapseki ilçelerinde sebze ekim alanlarına arazi çıkışları yapılmıştır. Bu ilçelerde, ilçeyi temsil edecek şekilde 254 
Türk. Biyo. Mücadele Derg.

Kasap, 2020, 11 (2): 253-260

seçilen alanlara 2011-2015 yıllarında, Mayıs, Temmuz ve Eylül aylarında, üretim sezonu içerisinde aylık toplam üç arazi çıkışı gerçekleştirilmiştir. Ziyaret edilen alanların genelde ilaçlamanın yapılmadığı alanlar olmasına özen gösterilmiş ancak ilaçlama yapılan alanlardan da örnekler alınmıştır. Çalışmalar süresince periyodik arazi çıkışların dışında, farklı zamanlarda yapılan arazi çalışmalarında toplanan örnekler ve üreticilerden gelen örnekler de değerlendirmeye alınmıştır. Bu arazi çıkışlarında her bahçeden, bahçenin büyüklüğüne bağlı olarak 50 ile 100 yaprak toplanarak gazete kâğıtlarına sarılıp, plastik torbalarda buz kutusu içerisinde Çanakkale Onsekiz Mart Üniversitesi, Ziraat Fakültesi, Bitki Koruma Bölümüne getirilmiştir. Bölüme getirilen örnekler incelenene kadar $+4^{\circ} \mathrm{C}$ sicaklıkta buzdolabında saklanmıştır. Toplanan yaprakların her iki yüzeyi stereobinoküler mikroskop altında incelenerek üzerindeki akarlar \% 70'lik etil-alkol içerisine alınmıştır. Daha sonra akarların Düzgüneş (1980)'e göre kalıcı preparatları hazırlanmıștır. Kalıcı preparatları yapılan türler Dr. Sultan ÇOBANOĞLU ve Dr. İsmail KASAP tarafindan, Arutunjan (1977), Chant, (1957), Chant \& Yoshida-Shaul (1987), Faraji et al. (2011)'den yararlanılarak teşhis edilmiştir.

\section{Bulgular ve tartışma}

Çanakkale ili sebze alanlarında yapılan sürvey çalışmaları sonucunda beş akar türü bölgedeki sebze alanlarında önemli avcı türler olarak belirlenmiştir. Bu akarlar içerisinde ise Phytoseiidae familyasından dört tür saptanmıştır (Çizelge 1). Avcı türlerden, Phytoseiidae familyası içerisinde yer alan Neoseiulus californicus (McGregor) ve Typhlodromus athiasae Porath and Swirski, bölgedeki sebze alanlarında özellikle de domates alanlarında en yaygın avcı türler olarak dikkati çekmiştir. Diğer bir avcı akar türü olan Phytoseiulus persimilis Athias-Henriot ise Çanakkale ili sebze alanlarında ve özellikle domates alanlarında saptanmıştır. Bu avc1 akar kırmızı̈rümceklere özelleşmiş olup ve tüm dünyada kırmızı̈rümceklerin en etkin avcısı olarak bilinmektedir. Bu çalışmada Çanakkale Merkeze bağlı Kumkale, Tevfikiye, Halileli ve Çıplak köylerinde (Batakovası), ayrıca Eceabat ilçesinde domates üretim alanlarında saptanmıştır (Çizelge 1). P. persimilis' in sebze yetiştiriciliğinin en yaygın yapıldığı bu alanlarda saptanması zararlı akarların biyolojik mücadele imkanları açısından oldukça ümit var bir gelişme olmuştur. Çanakkale ili domates alanlarında saptanan diğer bir avcı akar ise Gerlengeç köyünde (Biga) saptanan Proprioseiopsis messor (Wainstein)'dur. Ayrıca çalışmalar süresince Phytoseidae familyası dışında, Stigmaeidae familyasına bağlı avcı akar Zetzellia mali (Ewing) diğer bir avcı tür olarak saptanmıştır. Çalışmalar sonucunda Çanakkale sebze alanlarında yapılan sürvey çalışmalarından elde edilen türlerin toplanma yerleri, zamanı, toplandığı bitki ve birey sayısını belirten kayıtlar aşağıda familya bazında toplanarak verilmiştir. 
Çanakkale ili sebze alanlarındaki avcı akar türleri

Familya: Phytoseiidae

Alt Familya: AMBLYSEIINAE MUMA

Cins: Neoseiulus Hughes

Tür: Neoseiulus californicus (McGregor, 1954)

İncelenen materyal: Biga, Çanakkale, 17.11.2011, Solanum lycopersicum L. (1ㅇ): Lapseki, Çanakkale, 20.08.2011, S. lycopersicum L. (19): Solanum melongena L. (2ㅇ).

Cins: Proprioseiopsis Muma

Tür: Proprioseiopsis messor (Wainstein, 1960)

İncelenen materyal: Gerlengeç, Biga, Çanakkale, 17.11.2011, S. lycopersicum L. (2 + ): Gerlengeç, Biga, Çanakkale, 17.11.2011, S. lycopersicum L. (1 + ):

Cins: Phytoseiulus Evans

Tür: Phytoseiulus persimilis Athias-Henriot, 1957

İncelenen materyal: Eceabat, Çanakkale, 27.10.2009, S. lycopersicum, (2P), Malva vulgaris, Rubus fruticosus, S. nigrum (6ㅇ); Halileli, Merkez, Çanakkale, 25.09.2019, S. melongena L. (6ㅇ); S. lycopersicum L. (7ㅇ); Civler Köyü, Halileli, Merkez, Çanakkale, 15.10.2015, Phaseolus vulgaris L. (5 $)$; Tevfikiye, Merkez, Çanakkale, 20.09.2017, S. melongena L. (3ㅇ); Kumkale, Merkez, Çanakkale, 20.10.2019, S. melongena L. (5 ); Kangirl1, Çanakkale, 11.09.2018, S. lycopersicum L. (5ㅇ).

Alt Familya: TYPHLODROMINAE WAINSTEIN

Cins: Typhlodromus Scheuten

Alt Cins: Typhlodromus Scheuten

Tür: Typhlodromus (Typhlodromus) athiasae Porath \& Swirski, 1965

İncelenen materyal: Özbek Köyü, Çanakkale, 20.10.2009, 16.06.2010, 13.08.2010, 17.09.2010, 07.04.2011, 03.06.2011, 14.07.2011, 08.09.2011, 28.08.2011 S. lycopersicum, (9): Umurbey, Lapseki, Çanakkale, 20.10.2009, 17.09.2010, 03.06.2011, 08.09.2011, S. lycopersicum (3): Palamutoba Köyü, Bayramiç, Çanakkale, 24.11.2010, S. lycopersicum (1 + ): Ahmetçeli, Bayramiç, Çanakkale, 24.11.2009, S. lycopersicum (8ㅇ): 
Türk. Biyo. Mücadele Derg.

Kasap, 2020, 11 (2): 253-260

Familya: Stigmaeidae

Tür: Zetzelia mali (Ewing 1917)

İncelenen materyal: Musaköy, Çanakkale, 20.10.2010, S. lycopersicum (1 9 ): Özbek Köyü, Çanakkale, 20.10.20011, S. lycopersicum (2文): Umurbey, Lapseki, Çanakkale, 17.09.2010, 03.06.2011, S. lycopersicum (5우):

Bu konuda yapılan çalışmalardan, Can (2004) Antalya ili sera alanlarında zararlı faydalı akar üzerine yaptığı çalışmada, Tydeidae familyasından Pronematus ubiquitus (Mc Gregor), Phytoseiidae familyasından Euseus scutalis (AthiasHenriot), Amblyseus stipulatus Athias-Henriot Amblyseus bicaudus Waistein ve Laelapidae familyasından Hypoaspis miles Berlese belirlemiştir. Yeşilayer \& Çobanoğlu (2011), İstanbul ili park ve süs bitkileri üzerine yaptıkları çalışmalarda Phytoseiidae familyasına bağlı 11 predator akar türü belirlemişler ve bu akarlar içerisinde en yaygın türün ise $T$. (T.) athiasae olduğunu bildirmişlerdir. Kasap et al. (2013), Çanakkale ve Balıkesir illerinde bulunan predatör akar türlerini belirlemek amacıyla yaptıkları çalışmalarda Phytoseiidae familyasından 9 cinse bağlı 17 tür belirlemişler ve bu türler içerisinde T. athiasae'yi en yaygin phytoseiid türü olarak bildirmişlerdir. Kumral \& Çobanoğlu (2014), Türkiye'nin Kuzey batısında bulunan Bursa, Yalova ve Orta Anadolu'da yer alan Ankara illerinde 2009-2011 y1lları arasında domateslerdeki akarların biyolojik çeşitliliği ve popülasyon dalgalanmasının değerlendirildiği bir çalışmada 14 familyaya ait 34 zararlı, avcı ve nötr akar türü belirlemişlerdir. Bu türler içerisinde Phytoseiidae familyasına bağ ${ }_{1}$ avc1lardan Neoseiulus barkeri Hughes (Acari: Phytoseiidae) baskın tür olarak bildirmişlerdir. Kumral \& Çobanoğlu (2016), Türkiye'nin farklı ekolojilerine sahip Bursa ve Ankara illerinde patlıcan üretim alanlarında yaptıkları çalışmalarda Phytoseiidae familyasından 11 tür belirlemişler ve bu türler içerisinde $N$. californicus'un en yaygın tür olduğunu bildirmişlerdir.

Çanakkale ili sebze alanlarında yapılan bu çalışmalar sonucunda, belirlenen bu türlerin ileride yapılacak biyolojik mücadele çalışmaları açısından oldukça umut verici olduğu ve bu çalışmalara temel oluşturması açısından oldukça önemli olduğu düşünülmektedir. 
Çanakkale ili sebze alanlarındaki avcı akar türleri

Çizelge 1. Çanakkale ili sebze alanlarında tespit edilen avcı akar türlerin dağılımları

Table 1 . The distribution of predatory mite species on the vegetable areas of Canakkale province

\begin{tabular}{|c|c|c|c|c|c|}
\hline & & \multicolumn{4}{|c|}{ Akar türleri } \\
\hline & \multicolumn{4}{|c|}{ Phytoseiidae } & Stigmaeidae \\
\hline İlçeler & $\begin{array}{l}\text { Neoseiulus } \\
\text { californicus }\end{array}$ & $\begin{array}{c}\text { Typhlodromus } \\
\text { athiasae }\end{array}$ & $\begin{array}{l}\text { Phytoseiulus } \\
\text { persimilis }\end{array}$ & $\begin{array}{c}\text { Proprioseiopsis } \\
\text { messor }\end{array}$ & $\begin{array}{l}\text { Zetzellia } \\
\text { mali }\end{array}$ \\
\hline Merkez & + & + & + & - & + \\
\hline Biga & - & - & - & + & - \\
\hline Lapseki & + & + & - & - & + \\
\hline Ezine & - & - & - & - & - \\
\hline Bayramiç & + & + & & & - \\
\hline Ayvacık & - & - & - & - & - \\
\hline Eceabat & - & - & + & - & - \\
\hline Gelibolu & - & - & - & - & - \\
\hline
\end{tabular}

${ }^{(+)}$Çalışmalar süresince akarların toplandığı alanlar.

${ }^{(-)}$Çalışmalar süresince akarların bulunamadığı alanlar.

\section{Kaynaklar}

Anonymous 2019. Tarım ve Köy İşleri Bakanlığı, Çanakkale Tarım İl Müdürlüğü verileri. Çanakkale.

Arutunjan E.S. 1977. Key to Phytoseiid mites of Agricultural Crops in the Armenian SSR. Publishing House of the Academy of Sciences, Armenian SSR Erevan, pp 6-177.

Can M. 2004. Antalya ili Kumluca yöresinde sebze üretimi yapılan plastik ve cam seralarda bulunan akar (Acarina) türlerinin, tanımı, konukçuları ve yoğunluklarının belirlenmesi üzerine araştırmalar. Yüksek Lisans Tezi, Ankara Üniversitesi, Fen Bilimleri Enstitüsü, 99s.

Chant D A 1957. Descriptions of some phytoseiid mites (Acarina, Phytoseiidae). Part I. Nine new species from British Columbia with keys to the species of British Columbia. Part II. Redescriptions of eight species described by Berlese. The Canadian Entomologist, 89(7): 289-308.

Chant D. A. \& E.Yoshida-Shaul 1987. A world review of the soleiger species group in the genus Typhlodromus scheuten (Acarina:Phytoseiidae). Canadian Journal of Zoology, 65: 1770-1804.

Çobanoğlu S. 1989. Some phytoseiid mite species (Acarina: Phytoseiidae) determined in citrus orchards in some regions of Turkey. Turkish Journalof Entomology, 13: 163-178.

Çobanoğlu S. 1992. An annoted list of mites on hazel of Turkey. Israel Journal of Entomology, 25: 35-40.

Çobanoğlu S. 1997. New phytoseiid mites (Acarina: Mesostigmata) for Turkish fauna. Turkish Journal of Agricultural and Forestry, 21: 361-370.

Çobanoğlu S. 2004. Phytoseiid mites (Mesostigmata: Phytoseiidae) of Thrace, Turkey. Israel Journal of Entomology, 34: 83-107. 
Türk. Biyo. Mücadele Derg.

Kasap, 2020, 11 (2): 253-260

Çobanoğlu S., C. Uysal, \& M. E. Ökten 2003. The complex of the beneficial mite fauna of ornamental trees and shrubs in Ankara. Entomologist's Monthly Magazine, 139: 7-12.

Düzgüneş Z. 1963. New mite species for Turkey. Plant Protection Bulletin, 3: 237-246.

Düzgüneş Z. 1977. The Phytophagous mites on different economic plants and their control in Çukurova. Journal of Çukurova University, Faculty of Agriculture, 91: 1-25.

Düzgüneş Z. \& S. Kılıç 1983. Determination of phytoseiidae species in important apple growing areas of Turkey and studies on the effectiveness of the most important of them on Tetranychus viennensis Zacher. Doğa, 7: 193-205.

Ecevit O. 1977. Morphological Studies on Amblydromella kazachstanicus Wainst. 1958 (Acarina: Phytoseiidae). Journal of Faculty of Agricultural Atatürk University, 8: 23-28.

Faraji F. S. Çobanoğlu \& İ. Çakmak 2011. A checklist and a key for the Phytoseiidae species of Turkey with two new species records (Acari: Mesostigmata). International Journal of Acarology, 37 (1): 221-243.

Göksu M.E. 1968. Research on the biology and control of Tetranychus vienensis Zacher (Acari: Tetranychidae) in the Region of Marmara. Plant Protection Bulletin, 8:194-213.

Göven M.A., B. Güven \& S. Çobanoğlu 2002. Evaluation of vineyards for the predatory mite population densities with IPM and conventional (Control Systems) treatments in Izmir (Menemen) and Manisa (Saruhanl1) provinces. In proceedings of the Fifth Turkish National Congress of Biological Control, Erzurum, pp 319-326.

İncekulak R. \& O. Ecevit 2002. A research on determination of harmful and beneficial mite species in apple orchards in Amasya and their population densities. In proceedings of the Fifth Turkish National Congress of Biological Control, Erzurum,, pp 297-314.

Jeppson L.R., H.H. Keifer \& E.W. Baker 1975. Mites Injurious to Economic Plants. University of California Press, California, 614 p.

Kargöz B. \& İ. Kasap 2011. Çanakkale İli Domates Alanlarında Zararlı Kırmızıörümcek Tetranychus cinnabarinus Boisduval (Acari: Tetranychidae)' un Popülasyon Gelişmesi. Türkiye IV. Bitki Koruma Kongresi Bildirileri, Kahramanmaraş, pp 210.

Kasap İ. \& S. Çobanoğlu 2007. Mite (Acari) Fauna in Apple Orchards of Around The Lake Van Basin of Turkey. Turkish Journal of Entomology, 4(2): 89-98.

Kasap İ., S. Çobanoğlu \& S. Pehlivan 2013. Çanakkale ve Balıkesir illeri yumuşak çekirdekli meyve ağaçları ve yabancı otlar üzerinde bulunan predatör akar türleri. Türkiye Biyolojik Mücadele Dergisi, 30: 109-124.

Kumral A. \& S. Çobanoğlu 2014. Patlıcanda Akar (Acari) Biyolojik Çeşitliliği ve Baskın Türlerin Popülasyon Dalgalanması. Tarım Bilimleri Dergisi, 22: 261-224.

Kumral A. \& S. Çobanoğlu 2016. The biodiversity and population fluctuation of plant parasitic and benificial mite species (Acari) in tomato fields of Ankara, Bursa and Yalova provinces. Turkish Journal of Entomology, 38(2):197-214.

Şekeroğlu E. 1984. Phytoseiid mites (Acarina: Mesostigmata) of Southern Anatolia, their biology and effectiveness as a biological agents on strawberry plant. Doğa, 8: 320-336 .

Uslu H. 2012. Pas akarı Aculops lycopersici (Massee)'nin Çanakkale ili domates alanlarında popülasyon gelişmesi ve predatörlerinin belirlenmesi üzerine bir çalışma. Yüksek Lisans Tezi, Çanakkale Onsekiz Mart Üniversitesi, Fen Bilimleri Enstitüsü, Çanakkale.

Uysal C., S. Çobanoğlu \& M.E. Ökten 2001. Determination of Tetranychoidea (Acari: Prostigmata) species harmful in the Park Area of Ankara. Turkish Journal of Entomology, 25: $147-160$

Yeşilyanar A. \& S. Çobanoğlu 2011. The distribution of predatory mite species (Acari : Phytoseiidae) on ornamental plants and parks of Istanbul, Turkey. Turkish Journal of Entomology, 1(3): 135-143. 
Çanakkale ili sebze alanlarındaki avcı akar türleri

Yiğit A. \& N. Uygun 1981. Studies on the determination of benefical and injurious fauna of apple orchards in Adana, Içel and Kahramanmaraş Provinces. Plant Protection Bulletin, 22: $163-178$.

Yanar D. \& O. Ecevit 2005. Plant injurious and predatory mite species in apple (Malus communis L.) orchards in Tokat province. Journal of Faculty of Agricultural Ondokuz Mayls Universitesi, 20: 18-23. 